\title{
Caring the Cancer Caregivers in the Era of COVID-19 Outbreak
}

\section{Seema Mishra ${ }^{1}$, Swagata Biswas ${ }^{1}$, Shikhar More ${ }^{2}$, Ragahv Gupta ${ }^{1}$, Sachidanand Jee Bharti ${ }^{1}$, Rudranil Nandi ${ }^{3}$}

${ }^{1}$ Department of Oncoanaesthesia \& Palliative medicine, Dr. BR Ambedkar Institute Rotary Cancer Hospital, All India Institute of Medical Sciences, Delhi, India. ${ }^{2}$ Consultant, Department of Anaesthesia, Chitranjan National Cancer Institute, Kolkata. ${ }^{3}$ Consultant- Anaesthesia \& Critical Care at Tata Medical Center, Kolkata.

\begin{abstract}
As caring model of cancer patients has shifted to family centered model during the pandemic of COVID 19, it has caused immense increase in the needs of the caregivers. Thus, while providing a holistic care for cancer patients we need to understand the specific alterations in needs of caregivers due to pandemic. Thus, in this narrative review, we focus on addressing different needs of cancer caregivers in context of the on-going pandemic and preparedness strategy to meet those unmet needs.
\end{abstract}

Keywords: Cancer- caregiver- COVID-19

Asian Pac J Cancer Care, 5 (Suppl 1), 203-208

Submission Date: 07/07/2020Ａcceptance Date: 08/09/2020

\section{Introduction}

World is facing presently a pandemic due to outbreak of novel corona virus (COVID-19) infection. The world health organization (WHO) has declared it as a global pandemic on $11^{\text {th }}$ March, 2020 [1]. This has tremendously strained our health care delivery systems in various sectors. Standing in the middle of the pandemic, we need to prepare ourselves for maintaining the continuity of our services to special groups of patients who are more vulnerable. Cancer patients have been identified to have a higher risk of COVID-19 infection [2] and thus their caregiving needs special attention amidst the pandemic. Care for advanced cancer patients is a holistic approach. Caregivers are integral part of this holistic approach of care. Caregiving to cancer patients is an extremely demanding job as it needs full time attention throughout the trajectory of the disease. The intricacies and multiplicities of the needs of caregivers depend upon type of disease, stage, and treatments of diseases. The initial 6 months after diagnosis of cancer is usually the most stressful period for the caregivers [3]. Perception of the job also varies from person to person. While some caregivers find the job extremely

system of the caregivers also influences the needs of the caregiving. Female spouse, lack of support from other family members has been found to have increased needs for caregivers [5-6]. Communication process between caregivers, patients and health care professionals is also quite challenging and needs specific attention [7]. The community supports, access to health care facilities are the most useful aids to meet these unique needs of the caregivers [8].

During pandemic, the restriction of mobility, social distancing norms and lockdown is expected to strain the conventional support systems of the caregivers significantly. Thus, in view of the on-going pandemic, the different needs of caregivers should to be reviewed. There are only a few literatures which addresses the specific changes in the caregiver needs of cancer patients amidst the era of a pandemic. In this narrative review we have focussed on the specific needs, barriers and solutionsfor the caregivers of cancer patients in context of the on-going COVID-19 pandemic. gratifying, some feel extremely burned out physically, emotionally, economically and socially [4]. Support

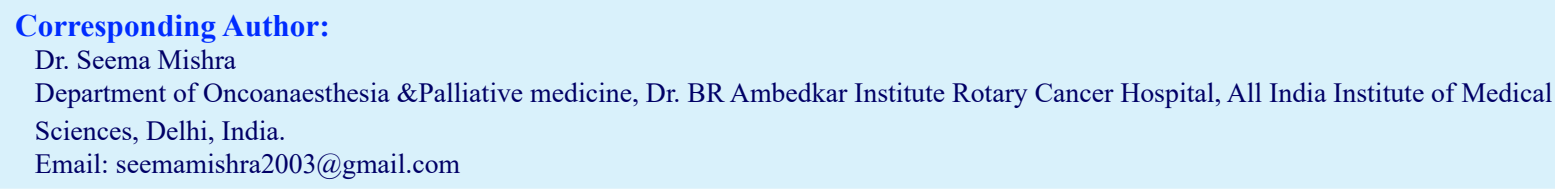

Email: seemamishra2003@gmail.com 
B. Specific needs and solutions for caregivers of cancer patients amidst the pandemic

During the pandemic, a family and caregivers centered care model has become the major care process for patients with chronic debilitating diseases [9]. Caregivers include any person (relative or friends) who is significantly associated with providing assistance to the patients with a chronic terminal illness [10]. Given et al. [11] described caregivers burden as "a multidimensional biopsychosocial reaction resulting from an imbalance of care demands relative to caregivers' personal time, social roles, physical and emotional states, financial resources, and formal care resources given the other multiple roles they fulfill." Thus, the needs of caregivers of cancer patients, which are expected to be altered by the pandemic situation, are multifaceted and summarized in Table 1. These factors are interdependent and often one is influenced by another (Figure 1). They are described as follows:

1. Support for physical care of the patients.

2. Support for social assistance

3. Support for economic distress.

4. Support for Psychological impacts.

5. Support for protecting themselves from infection.

Support for physical care of the patient

Terminal cancer patients need assistance from caregivers for managing many of their physical symptoms [12]. Caregivers take part in providing medications to the patients, dose adjustments, tube feeding, monitoring of symptoms and side effects of treatments and managing stress and anxiety of the patients. They also do act as a coordinator for home care between physician and patient and also take part actively in decision making about treatment. This process needs a thorough guidance and education of the caregivers, without which it can rather negatively affect the symptoms management of the patients [13]. But, in an era of pandemic this education and providing assistance may be quite challenging as conventional access to the health care systems are restricted. Due to infection control strategies of the hospitals, it is desired to decrease frequent hospital visits by caregivers. Thus the most feasible solution to this is integration of digital technology.

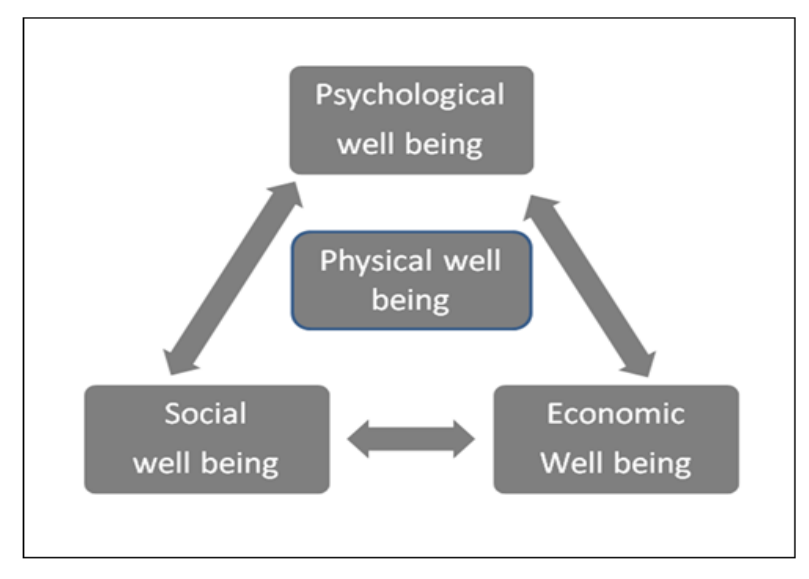

Figure 1. Interdependent Needs of Cancer Givers During Pandemic
A face to face teleconsultation visits can be arranged for personalized training of caregivers. Video demonstration and monitoring of the caregivers during the process of care, e.g. wound care, giving medications and feeding etc may improve the outcome of care and confidence of the caregiver. With invent of new technologies and mobile based applications (e.g. Tapcloud) this process of assistance to caregivers has become more dynamic, even at remote locations [14]. The only limitation for real time assistance to caregivers is a limited access of technology to rural areas, especially in developing countries. In that case, a caregiver module should be designed addressing the common assistance needs for symptoms management and should be dispensed among them, whenever they do visit the hospital [15].

\section{Support for social assistance}

A social support is a form of emotional, physical or informational support system that can be provided by any family members, neighborhood, friends or community [16]. The supports can be actually received or even being simply perceived to be available at the time of need. For caregivers of cancer patients social support is an indispensible part of their journey. The impact of availability of social support is directly related with the stress, psychological well-being and ultimately physical health of the caregivers [17]. Some of the major social supports the caregivers need while caring their patients is: transportation, managing daily activities and psychological support by family members and peer groups.

The current pandemic tends to break this social support system of caregivers due to the social distancing norms. Social isolation can generate feeling of loneliness and disconnectedness from rest of the society and thus significantly decrease their quality of life. Moreover, social stigma is a major contributing factor for lack of social support during the pandemic. Family with a member who has recovered from COVID-19 infection, a person with cough due to other medical condition or a family having a frontline worker as a member often face rejection by rest of the society [18]. The key to maintain continuity of social support for cancer caregivers are educating about the myths and facts about the COVID-19 disease, creating an advanced plan and generate alternative platforms for social support. Family members should maintain physical distancing instead of social distancing. Mobiles and digital technologies are quite useful to keep the family members strings attached with each other. A caregiver should identify their potential supports from social group way ahead and communicate them to avoid last moment hassles. Peer support group meeting on a digital platform, web based networks, digital information centers and social media are the useful alternative platforms to access both the perceived and actual social support [19].

\section{Support for economic assistance}

Economic strains have been one of the major concerns for caregivers during pandemic. Raising the cost of cancer treatment is a significant financial burden for the cancer patients [20]. During the pandemic several 
Table 1. Different Needs, Problems and Solutions for Cancer Caregivers During Pandemic

\begin{tabular}{|c|c|c|}
\hline Needs & Problem during pandemic & Intervention \\
\hline Physical well being & $\begin{array}{l}\text { Protection from infection. } \\
\text { - Decreased availability of social support system } \\
\text { increase duration of caring }\end{array}$ & $\begin{array}{l}\text { Education of caregivers about DO'S and Don'ts, identify high risk } \\
\text { caregivers and provide them PPE for caring infected person, wear } \\
\text { homemade masks, limited visitors entry, practice hand hygiene. } \\
\text { - Identify the potential social supports and strengthen them. } \\
\text { Caregiving in rotation with other family members decrease physical } \\
\text { burn out, improve sleep and rest pattern. }\end{array}$ \\
\hline Social well being & $\begin{array}{l}\text { Lack of social support system for transportation, } \\
\text { daily activities, psychological support due to social } \\
\text { isolation. } \\
\text { Social stigma for infection. }\end{array}$ & $\begin{array}{l}\text { Identify potential source of social support, e.g. Peer group, other } \\
\text { family members, NGOs etc well in advance. } \\
\text { Use online digital platforms, social media for strengthening peer } \\
\text { support and social support. }\end{array}$ \\
\hline Economic well being & $\begin{array}{l}\cdot \text { Loss of job } \\
\cdot \text { Inadequate coverage by insurance }\end{array}$ & $\begin{array}{l}\text { Reassure and communicate with empathy. } \\
\text { Information about Government schemes and institutions, NGOs for } \\
\text { financial aid for cancer treatments. }\end{array}$ \\
\hline Psychological well being & $\begin{array}{l}\text { Fear of infection acute precipitate anxiety and } \\
\text { depression. } \\
\text { Sudden death of loved ones creates complex grief } \\
\text { reaction. } \\
\text { - Inadequate preparation may produce chronic } \\
\text { posttraumatic stress disorders } \\
\text { Limited access to conventional death rituals and } \\
\text { bereavement support }\end{array}$ & $\begin{array}{l}\text { Follow the principles of "psychological first aid" (SFA) } \\
\text { Compassionate communication, Refer to web based resources to } \\
\text { overcome challenges of communication during pandemic. } \\
\text { - Identify high risk patients for psychological distress, address and } \\
\text { acknowledge their concerns in a personalized manner, prepare them } \\
\text { for the inevitable deaths way before. } \\
\text { - Refer and involve spiritual leaders. } \\
\text { - Start early advanced care planning. } \\
\text { - Bereavement care for distressed caregivers through digital } \\
\text { technology or personalized letters. }\end{array}$ \\
\hline
\end{tabular}

people tend to lose a job as a result of global economic recession [21]. Moreover previous health insurance may not give coverage to this new illness of COVID-19. All these impose several economic burdens on the caregivers, which impact their psychological and physical well-being. Acknowledging their concern and assurance can decrease their anxiety and may improve the strains. They should be provided with the information about the different government aided organizations, schemes and non-government organizations (NGO) for cancer patients, which may provide some economic assistance to them [22]. Use of telemedicine should be maximized for them, as it will reduce the cost of transportation and pay cut due to absence from job.

\section{Support for psychological well-being}

Cancer caregivers have a significant amount of psychological burden throughout the disease trajectory. They have high incidence [23] of stress (66.1\%), depression (68.8\%) and anxiety $(72.3 \%)$. Female sex, extremes of ages, terminal stage of cancer, family functioning are predictor of high incidence of psychological distress among cancer caregivers [5]. Thus, during pandemic caregivers of cancer patients are expected to be more vulnerable for psychological impact than general population. Social isolation and quarantine augment the feeling of detachment from patient and other family members [24], who are the major social and psychological support system of the caregivers. Social stigma, guilt of transmitting disease to the loved ones, lack of social supports for transport, anticipatory fear of not being able to access the health care system in time of need, fear of disease recurrence and progression can precipitate acute anxiety, frustration, guilt and anger in the caregivers.

The world health organization (WHO) suggested the response strategy named as "psychological first aid" (PFA) for psychological support in humanitarian crisis [25]. The basic principles of this strategy can be adopted for cancer caregivers amidst pandemic. These include compassionate engagement of the caregivers in a nonintrusive manner; ensuring safety and comfort; stabilize and orient them emotionally; gather information to assess personalized needs of the caregivers; strengthening social support including family, friends and social organizations; provide information on stress reaction and coping strategies. Communication is the key to handle such distress of the caregivers. Their efforts should be acknowledged. They should be reassured that they are doing best possible thing for their loved ones in this extraordinary situation. Strengthening social support and economic stability enhance the coping process with anxiety and depression. Teleconsultation can be a useful to provide psychological assistance to the caregivers, providing them correct information and maintaining the social bond among family members over technological supports and social media is desirable. Web based groups for cognitive behavioral therapies can be useful to relieve the anxiety and distress.

Another major aspect is severe trauma due to illness and death of loved ones during pandemic. As terminal cancer patients are immunocompromised and prone to the infection, there may be acute detoriation of the patients. These sudden events can generate a complex grief reaction and post-traumatic stress disorder (PTSD) in caregivers [26]. There may be inadequate preparation and discussion for death. Thus caregivers of end of life care patients need special attention for grief management support. The grief can be anticipatory due to fear of death or disenfranchised due to guilt of spreading infection [26]. Moreover they often don't receive the chance to mourn with whole family while being in isolation or quarantine. Mandating the social isolation norms during post death rituals, restrict the family members to access the traditional death rituals.

Managing this grief and providing effective 
bereavement support involves identifying the high risk caregivers for psychological distress, early discussion about advanced care planning, adopting to self-care and bereavement support strategies. There is no standardized questionnaire to assess the caregivers' ability to handle the psychological distress during pandemic. Still, there are some validated tools that can be used to assess the caregivers at high risk of developing grief, e.g. Zarit Burden Caregiving Screening Interview [27], the Cancer Suppor tSource -Caregiver Distress Screening Instrument [28], Marwit-Meuser Caregiver Grief Inventory (MMCGI) [29] etc. High risk caregivers should receive personalized grief and post death bereavement support to prevent development of PSTD [26]. Advanced care planning (ACP) should start early involving caregivers, physicians and patients. Teleconsultation can be used to arrange such discussion. Communication can be found difficult due to inadequate priming and acute worsening condition of the patient. There are communication learning source on digital platform, which can be referred by the physician to break the ice of communication [30]. Choice of spiritual and cultural aspects as per the religion, ethnicity should be included in the ACP discussion. All the caregivers should be trained for self-care strategies for coping with the psychological burden, e.g. relaxation techniques, staying connected with other family members and friends via telephone technology, following didactic digital platforms to stay informed, avoiding panic creating social media, taking help other family members for caregiving in rotation to decrease burnout and take adequate rest, identifying the social supports and peer groups for help in emergency situation.

Cultural and spiritual supports are integral part of psychological support. Psychological distress produces hopelessness and frustration. Death rituals as per the ethical and cultural practices are restricted during pandemic. The religious leaders of concerned community can be involved for this process. Online spiritual sessions and reading religious materials should be accessed by the caregivers. Death rituals according to the individual culture and ethnicity should be allowed keeping the gatherings restricted among close family members only.

Bereavement support is essential for caregivers to prevent formation of post death complex grief [26]. Conventional death rituals for mourning and bereavement meeting are truncated during pandemic. A bereavement support by the health care workers can decrease the grief effectively. Thus, a bereavement family meeting on digital platform with face to face interaction with health care workers involved in the care of the patient can be arranged. Alternatively, a personalized bereavement letter for the family can be a tool for providing the bereavement support (Table 2).

\section{Support for protecting the caregivers from infection}

Caregivers are basically the first line health care workforce, who provide care to the vulnerable patients for COVID-19 infection or sometimes suspected or confirmed cases of COVID-19 among family members. Some caregivers are old age, have multiple comorbidities and high risk of COVID-19 infection [31]. It is important to protect the caregivers from infection during a pandemic. The World Health Organization (WHO) has issued an interim guidance for care of infected people at home [32]. The high risk caregivers or caregivers with an infected family member at home should be considered for distribution of personal protective eqipments (PPE) [33]. Rest all the caregivers should use homemade masks and perform frequent hand hygiene [34]. Number of visitors should be restricted at home. The infected person should not share the immediate space with other family members. But it is important to remember that physical distancing should be the practice for cancer patients than social isolation. Thus, caregivers should be connected to the patients and others family members through digital communication, even during isolation or quarantine.

\section{Preparedness for cancer caregivers: a " $7 S$ " strategy}

Cancer has an unpredictable disease trajectory. Thus caregiving role for cancer patients has its own share of challenges. Pandemic and nationwide lockdown has imposed more uncertainties to that. Thus it is important to prepare the caregivers beforehand to handle a crisis situation effectively. We propose a "7S" strategy to make them prepare for such crisis:

1. Stuff: Stockpile essential drugs for symptoms

Table 2. Summary of the Bereavement Services for Cancer Caregiver

\begin{tabular}{ll}
\hline Prophylactic Measures & Therapeutic Measures \\
\hline $\begin{array}{l}\text { 1. Communication: listen, acknowledge and understand their concerns and } \\
\text { emotion empathetically. }\end{array}$ & $\begin{array}{l}\text { 1. A bereavement evening with restricted gathering. } \\
\text { 2. A personalized bereavement letter or memento. }\end{array}$ \\
$\begin{array}{l}\text { 2. Identify high risk caregivers for development of post death grief e.g. old } \\
\text { age, alone in the family, already emotionally distressed, sudden death without } \\
\text { adequate preparation etc. }\end{array}$ & $\begin{array}{c}\text { 3. Always involve the physician to provide post death bereavement and } \\
\text { already has a good rapport with the caregiver. }\end{array}$ \\
3. Arrange personalized sessions and behavioural therapy for high risk \\
caregivers via web based portals. \\
$\begin{array}{l}\text { 4. Early discussion about goals of care and advanced care plans. } \\
\text { 5. Connection between caregiver and patient, other family members should } \\
\text { be kept intact with the use of virtual mediums, e.g. mobile, smartphones etc. } \\
\text { 6. Manage the symptoms at end of life; ensure dignity of death. } \\
\text { 7. Inform the caregiver the restrictions and formalities to arrange a funeral } \\
\text { during pandemic and plan accordingly. }\end{array}$ \\
\hline
\end{tabular}


management at least for one month, e.g. opioids, steroids, oral chemotherapy drugs etc.

\section{Space:}

- Make the house well ventilated and roomy as much as possible

- Plan how to use the rooms and available space if isolation and homequarentine is needed.

\section{Skills:}

- Prepare the caregivers for providing assistance to manage symptoms of the patients, e.g. providing medicines, subcutaneous injection, feeding through tubes, wound dressing etc.

- Prepare caregivers with communication skills to discuss the care goals, advanced care planning, communication skill with physician over telemedicine.

\section{Staff:}

- Plan with family members to care the patients in rotation.

- Identify social support sources beforehand and communicate with them.

- Identify sources of financial assistance, e.g. Government beneficiary schemes, nongovernment organizations (NGO).

- Arrange for work from home, if possible.

- Clarify coverage details of health insurances from company beforehand.

- Be informed about hospital helpline and teleconsultation numbers.

5. Social media:

- Be well equipped with the use of social media and other digital system to find social support, psychological sessions and education regarding the COVID-19 infection.

\section{Sensitization:}

- Sensitize and educate the caregivers about myths and facts, do's and don'ts about the COVID-19 infection prevention measures.

- Sensitize and prepare them about inevitable deaths with early discussion of advanced care planning.

7. Self-care:

- Take good sleep, food and rest.

- Use leisure activities to rejuvenate themselves.

- Take treatments and manage their own comordities adequately.

- Stay connected with patients, family members and friends maintaining the norms of physical distance. Use digital media as much as possible for that purpose.

- Take adequate preparation (e.g.: arranging masks, hand sanitizers etc.) for protecting themselves from infection.

-Seek for help whenever needed.
In conclusion, acute surge of cases and less health care workforce availability during pandemic has shifted the hospital based care model to the home based care model for cancer patients. So, caring the caregiversis an essential part while planning for the care of cancer patients and related policy formulation. Care of the cancer caregivers is a holistic approach which consists of social support, economical support, psychological support, support for symptom management of the patients and also protecting themselves from the infection. Overall wellbeing of the care givers are dependent upon all these domains and often one domain influences the other. The caregivers need to be well educated about their responsibilities, needs and possible resources to fulfill them. Telemedicine and web based methods to address the needs with empathetic communication can reduce their burden to a large extent effectively.

\section{References}

1. World Health Organization. WHO Director-General's opening remarks at the media briefing on COVID-19 - 11 March 2020. Available from: https://www.who.int/dg/ speeches/detail/who-director-general-s-opening-remarksat-the-media-briefing-on-covid-19---11-march-2020. Date accessed: 20/04/2020.

2. Liang W, Guan W, Chen R, Wang W, Li J, Xu K, Li C, Ai Q, Lu W, Liang H, Li S, He J. Cancer patients in SARSCoV-2 infection: a nationwide analysis in China. The Lancet Oncology. 2020 03;21(3):335-337. https://doi.org/10.1016/ s1470-2045(20)30096-6

3. Longacre ML, Ridge JA, Burtness BA, Galloway TJ, Fang CY. Psychological functioning of caregivers for head and neck cancer patients. Oral Oncology. 2012 01;48(1):18-25. https://doi.org/10.1016/j.oraloncology.2011.11.012

4. Girgis A, Lambert S, Johnson C, Waller A, Currow D. Physical, Psychosocial, Relationship, and Economic Burden of Caring for People With Cancer: A Review. Journal of Oncology Practice. 2013 07;9(4):197-202. https://doi. org/10.1200/jop.2012.000690

5. Stetz K. The relationship among background characteristics, purpose in life, and caregiving demands on perceived health of spouse caregivers. SchInqNursPract. 1989;3(2):133-53.

6. Stetz K. Caregiving demands during advanced cancer. The spouse's needs. Cancer Nurs. 1987;10(5):260-8.

7. Ellington L, Clayton MF, Reblin M, Donaldson G, Latimer S. Communication among cancer patients, caregivers, and hospice nurses: Content, process and change over time. Patient Education and Counseling. 2018 03;101(3):414-421. https://doi.org/10.1016/j.pec.2017.09.013

8. Shelby RA, Taylor KL, Kerner JF, Coleman E, Blum D. The Role of Community-based and Philanthropic Organizations in Meeting Cancer Patient and Caregiver Needs. CA: A Cancer Journal for Clinicians. 200207 01;52(4):229-246. https://doi.org/10.3322/canjclin.52.4.229

9. Kent EE, Ornstein KA, Dionne-Odom JN. The Family Caregiving Crisis Meets an Actual Pandemic. Journal of Pain and Symptom Management. 2020 07;60(1):e66-e69. https:// doi.org/10.1016/j.jpainsymman.2020.04.006

10. Breitbart WS, Alici Y. Psycho-Oncology. Harvard Review of Psychiatry. 2009 Nov;17(6):361-376. https://doi. org/10.3109/10673220903465700

11. Given B, Kozachik S, Collins C, DeVoss, et al, editors. Nursing care of older adult diagnoses: Outcome and 
interventions. St. Louis: Mosby.:pp. 679-695.

12. Ullgren H, Tsitsi T, Papastavrou E, Charalambous A. How family caregivers of cancer patients manage symptoms at home: A systematic review. International Journal of Nursing Studies. 2018 09;85:68-79. https://doi.org/10.1016/j. ijnurstu.2018.05.004

13. van Ryn M, Sanders S, Kahn K, van Houtven C, Griffin JM, Martin M, Atienza AA, Phelan S, Finstad D, Rowland J. Objective burden, resources, and other stressors among informal cancer caregivers: a hidden quality issue? Psycho-Oncology. 2010 Dec 22;20(1):44-52. https://doi. org/10.1002/pon. 1703

14. Bonsignore L, Bloom N, Steinhauser K, Nichols R, Allen T, Twaddle M, Bull J. Evaluating the Feasibility and Acceptability of a Telehealth Program in a Rural Palliative Care Population: TapCloud for Palliative Care. Journal of Pain and Symptom Management. 2018 07;56(1):7-14. https://doi.org/10.1016/j.jpainsymman.2018.03.013

15. de la Cruz M, Reddy A, Balankari V, Epner M, FrisbeeHume S, Wu J, Liu D, Yennuraialingam S, Cantu H, Williams J, Bruera E. The Impact of an Educational Program on Patient Practices for Safe Use, Storage, and Disposal of Opioids at a Comprehensive Cancer Center. The Oncologist. 2017 01;22(1):115-121. https://doi.org/10.1634/ theoncologist.2016-0266

16. Thoits PA. Stress and Health: Major Findings and Policy Implications. Journal of Health and Social Behavior. 2010 03;51(1_suppl):S41-S53. https://doi. org/10.1177/0022146510383499

17. García-Torres F, Jacek Jabłoński M, Gómez Solís Á, Moriana JA, Jaén-Moreno MJ, Moreno-Díaz MJ, Aranda E. Social support as predictor of anxiety and depression in cancer caregivers six months after cancer diagnosis: A longitudinal study. Journal of Clinical Nursing. 202001 14;29(5-6):9961002. https://doi.org/10.1111/jocn. 15123

18. Centers for Disease Control and Prevention. Coronavirus Disease 2019 (COVID-19).Cdc reducing stigma. https:// www.cdc.gov/coronavirus/2019-ncov/daily-life-coping/ reducing-stigma.html..

19. Given BA, Given CW, Sherwood PR. Family and Caregiver Needs over the Course of the Cancer Trajectory. The Journal of Supportive Oncology. 2012 03;10(2):57-64. https://doi. org/10.1016/j.suponc.2011.10.003

20. Oncology ASoC. Cancer Survivorship: Next Steps for Patients and Their Families. Alexandria, VA: American Society of Clinical Oncology; 2011..

21. Caregiving in the U.S. - this is a report, National Alliance for Caregiving. American Association for Retired Persons, Washington, DC2015 (Available from https:// www.caregiving.org/wpcontent/uploads/2015/05/2015 CaregivingintheUS_Executive-Summary-June-4_WEB.pdf. Accessed April 25, 2020)..

22. Financial Aid And Resource. http://cancerindia.org. in/financial-aid-and-resources/\#: :text $=$ Ministry $\% 20$ of $\% 20$ Health $\% 20 \% 26$ Family $\% 20$ Welfare $\% 2$ C $\% 20$ Government $\% 20$ of $\% 20$ India,assistance $\% 20$ to $\% 20$ the $\% 20$ poor $\% 20$ patients $\% 20$ suffering $\% 20$ from $\% 20$ cancer.

23. Areia NP, Fonseca G, Major S, Relvas AP. Psychological morbidity in family caregivers of people living with terminal cancer: Prevalence and predictors. Palliative and Supportive Care. 201802 26;17(03):286-293. https://doi.org/10.1017/ s1478951518000044

24. Holt-Lunstad J, Smith TB, Baker M, Harris T, Stephenson D. Loneliness and Social Isolation as Risk Factors for Mortality. Perspectives on Psychological Science. 2015 03;10(2):227237. https://doi.org/10.1177/1745691614568352
25. World Health Organization, War Trauma Foundation, and World Vision International. Psychological First Aid: Guide for Field Workers. Geneva: World HealthOrganization; 2011.https://www.who.int/mental_health/publications/ guide_field_workers/

26. Wallace CL, Wladkowski SP, Gibson A, White P. Grief During the COVID-19 Pandemic: Considerations for Palliative Care Providers. Journal of Pain and Symptom Management. 2020 07;60(1):e70-e76. https://doi. org/10.1016/j.jpainsymman.2020.04.012

27. Bédard M, Molloy DW, Squire L, Dubois S, Lever JA, O'Donnell M. The Zarit Burden Interview. The Gerontologist. 2001 Oct 01;41(5):652-657. https://doi. org/10.1093/geront/41.5.652

28. Shaffer K, Benvengo S, Zaleta A, et al. Feasibility and acceptability of distress screening for family caregivers at a cancer surgery center. OncolNurs Forum. 2019;46:159-69.

29. Marwit SJ, Chibnall JT, Dougherty R, Jenkins C, Shawgo J. Assessing pre-death grief in cancer caregivers using the Marwit-Meuser Caregiver Grief Inventory (MMCGI). Psycho-Oncology. 2008;17(3):300-303. https://doi. org/10.1002/pon.1218

30. Selman LE, Chao D, Sowden R, Marshall S, Chamberlain C, Koffman J. Bereavement Support on the Frontline of COVID-19: Recommendations for Hospital Clinicians. Journal of Pain and Symptom Management. 2020 08;60(2):e81-e86. https://doi.org/10.1016/j. jpainsymman.2020.04.024

31. Li X, Xu S, Yu M, Wang K, Tao Y, Zhou Y, Shi J, Zhou M, Wu B, Yang Z, Zhang C, Yue J, Zhang Z, Renz H, Liu X, Xie J, Xie M, Zhao J. Risk factors for severity and mortality in adult COVID-19 inpatients in Wuhan. Journal of Allergy and Clinical Immunology. 2020 07;146(1):110-118. https:// doi.org/10.1016/j.jaci.2020.04.006

32. World Health Organization. Interim Guidance for Implementing Home Care of People Not Requiring Hospitalization for Coronavirus Disease 2019 (COVID-19). https:/www.cdc.gov/coronavirus/2019-ncov/hcp/guidancehome-care.html..

33. Kent EE, Ornstein KA, Dionne-Odom JN. The Family Caregiving Crisis Meets an Actual Pandemic. Journal of Pain and Symptom Management. 2020 07;60(1):e66-e69. https:// doi.org/10.1016/j.jpainsymman.2020.04.006

34. World Health Organization. Advice on the use of masks in the context of COVID-19. Interim guidance 6 April 2020. Available from: https://www.who.int/publications-detail/ advice-on-the-use-of-masks-in-the-community-duringhome-care-and-in-healthcare-settings-in-the-context-of-thenovel-coronavirus-(2019-ncov)-outbreak. Date accessed: $20 / 04 / 2020$

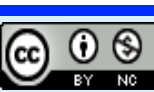

This work is licensed under a Creative Commons AttributionNon Commercial 4.0 International License. 